International Journal of Instruction e-ISSN: 1308-1470 • www.e-iji.net
July $2020 \bullet$ Vol.13, No.3

p-ISSN: 1694-609X

pp. $665-678$

Received: 15/04/2019

Revision: 22/02/2020

Accepted: 27/02/2020

OnlineFirst:09/05/2020

\title{
Learning Model of Undergraduate Students: Confirmatory Factor Analysis
}

\section{Pariyaporn Tungkunanan}

Faculty of Industrial Education and Technology, King Mongkut's Institute of Technology Ladkrabang (KMITL), Bangkok, Thailand, pariyaporn.tu@kmitl.ac.th

The research aimed to find the learning model of the undergraduate students by Confirmatory Factor Analysis (CFA). The objective was design learning model. The Methods of this Study process to find the learning model of the undergraduate students is divided into two phrases. The 1st phrase: the preliminary study and the 2nd phrase: Confirmatory Factor Analysis (CFA). The result found that learning model of the undergraduate that support capability of the learners to be qualified graduates and competitive in the international consist of (1) expectation, (2) planning by experience and reflective observation, (3) attention, retention and memory storage, (4) learning method, (5) retrieval by reproduction or making concept by conclusion principles, and (6) motivation or reinforcement.

Keywords: learning model, learning of undergraduate students, confirmatory factor analysis, design learning, learning method

\section{INTRODUCTION}

Sustainable Development Goals: SDGs of the UNESCO which covered 15 years (20152030) consisted of 17 goals. The fourth goal is about education management "making education assurance to ensure that all have equal education and support lifelong learning (Quality Education)". The fourth goal consisted of ten objectives, and the 4.4th Sustainable Development (SDG4.4) is to increase the development of life skill, good working and being an entrepreneur for youth and adult (The United Nation, 2015). The data of United Nations Educational, Scientific and Cultural Organization: UNESCO (United Nations Educational, Scientific and Cultural Organization: UNESCO. ,2016) showed that there is nowadays 73 million jobless youth and 1.44 billion are low skill labours. The graduates are not prepared to work. Also, there will be at least 475 million new job positions in the next decade. The report of competitive ability index made by the International Institute for Management Development: IMD showed that the 15th indicator: competitive economic ability in higher education of Thailand during 20132017 was continuously lower than those 40 from 63 countries. (Office of The Education Council, 2017).

Citation: Tungkunanan, P. (2020). Learning Model of Undergraduate Students: Confirmatory Factor Analysis. International Journal of Instruction, 13(3), 665-678. https://doi.org/10.29333/iji.2020.13345a 
According to the data above, it is necessary for the higher education institutions in Thailand, which are the main sources to produce labour to support the competition of the country, have to adapt them in learning management to improve the ability of human resource in the country. Kehm (Kehm, Barbara M., 2001) presented the concept that "higher education institutions have to manage learning that is action-oriented and focus on learning to learn. It is understanding in the self-learning process and being able to evaluate what has learned and the development. The experts in higher education have to know not only the specific knowledge but also the learning process. Besides, the experts have to facilitate and assist the learners as well as coach them to be a reflective practitioner." The concept is consistent with Hadwin Winne, (Knapper, Christopher K. and Cropley ,Arthur. J., 2000) who stated that "higher education should not only teach the learners only knowledge in the curriculum but also support the learners to improve strategies to search for knowledge and solve the general problem both during and after education. Besides, the higher education institutions have to improve study skills that are necessary for lifelong learning of the learners. The higher education institutions have to focus on self-learning and reflective learning by the teaching ways that support the learners to have proper learning skills called process-oriented. The concept of processoriented has four main principles; 1 ) to let the learners manage their learning process step by step, 2) to focus on making knowledge, 3) the teachers help the learners adapt knowledge and skill by opinion reflection and discussion, and 4) to make the learning process and learning achievement social phenomenal. The reflection of learning adjusting of the higher education institution in Thailand can be considered from the higher education development plan 11th (2012-2016) which stated that " $\mathrm{G}=$ Graduated with Quality and Social Responsibility." Besides, the learning process of the graduates should be changed to meet the standards frame of the graduate at least five standard skills; 1) morality, 2) knowledge, 3) wisdom, 4) relation between person and responsibility, and 5) numeral analysis, communication and information technology. Moreover, the learners should have a new vision of learning and can have self-lifelong learning, voluntary mind, and responsibility to society, be valuable world people and keep the cultural identity and Thai local wisdom, which is consistent with the Sufficiency Economy Philosophy. The graduates should have a balance between being good at work and kindness. Also, the graduates should have responsibility, physical and mental happiness for themselves and the society, as well as be able to adjust themselves to the changing work." (Office of the Higher Education Commission, 2013)

The concept above can be concluded that paradigm of learning management has to be changed from objectivism, which believes that the learners can learn from knowledge transfer from the teachers, to be constructivism, which believes that there should be knowledge exchanging and agreement from various learners, and the teachers' role as facilitator. Therefore, the teachers should realise and understand the learning frame of the learners, in order to use the data in learning design, to response learning of the learners.

King Mongkut's Institute of Technology Ladkrabang (KMITL), Bangkok, Thailand [8] is the institute under the Higher Education Commission that saw the importance of learning, and specified the graduates production goals "the graduates of King Mongkut's 
Institute of Technology Ladkrabang (KMITL) are qualified to the professional standard and international, and be accepted by the society and the employers." Therefore, learning model of the undergraduate students from King Mongkut's Institute of Technology Ladkrabang (KMITL) the objective was design learning model focused on finding learning model of the undergraduate students by Confirmatory Factor Analysis (CFA) in the form of knowledge that the teachers can use the research result to improve learning design to support the capability of the learners to be ready to work and compete in the international level.

\section{LITERATURE REVIEW}

The research aims to find the learning model of undergraduate students by Confirmatory Factor Analysis (CFA), and review the literature involved with learning.

The Definition and Concept of Learning

Learning is a process of changing the behaviour of human or animal and responding to situation, experience or external environment. Human's learning competence consisted of (1) verbal information (2) intellectual skills (3) cognitive strategies (4) motor skills and (5) attitudes (Robert M. Gagné, 1974), (Robert M. Gagné, Briggs, and Wagner, 1992).

The Concept of Learning Process Bandura [11] described that there are two steps of the social learning process by observation and imitation. The first step "acquisition" consisted of

\section{Attention}

2. Retention

The second step "performance" consisted of

\section{Reproduction}

4. Motivation

Gagné (1974) divided learning situation into two parts internal events and external events that operated by each teacher. Both parts have stepped process as figure 1 


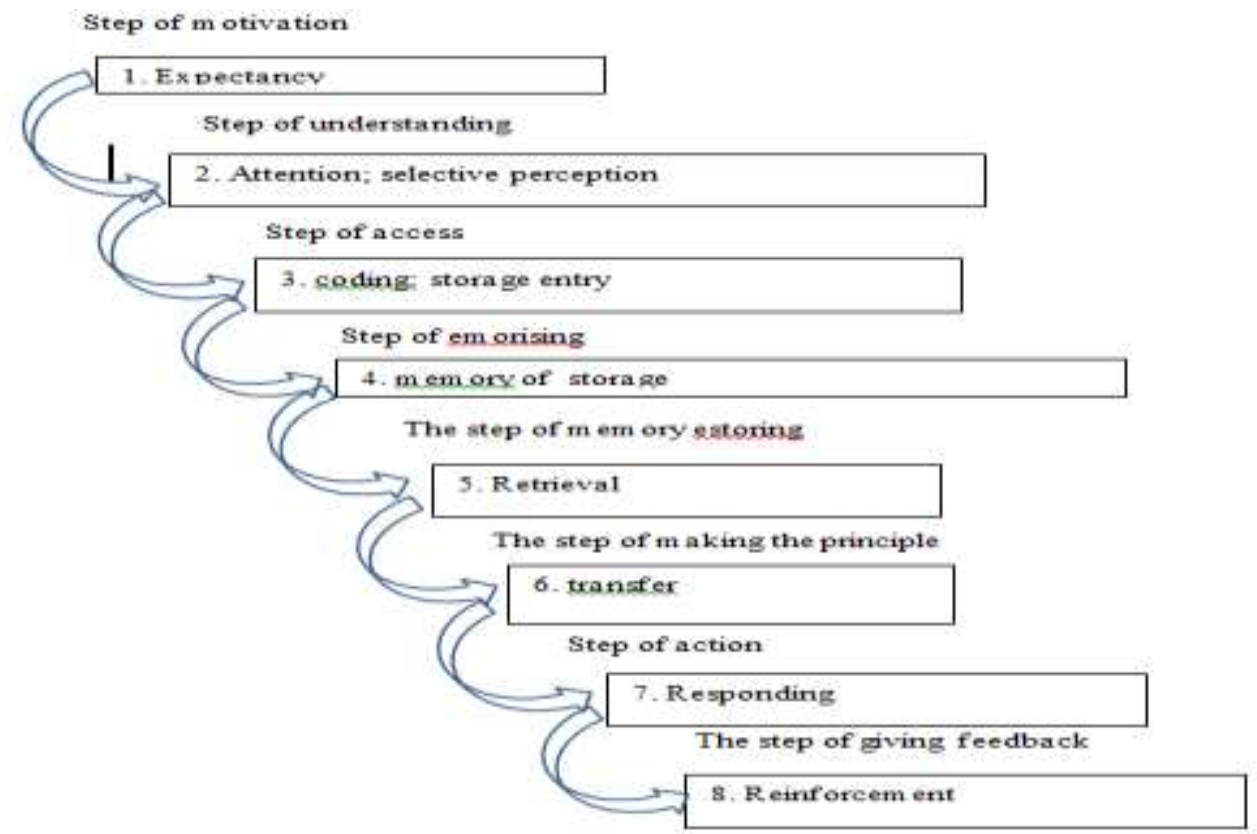

Figure 1

Learning Process by the Concept of Robert M .Gagné (1974)

David A. Kolb and other (1984) described learning process ELT )Experiential Learning Theory (of people noticeably. He stated that the learning process is a circle with four steps as figure 2

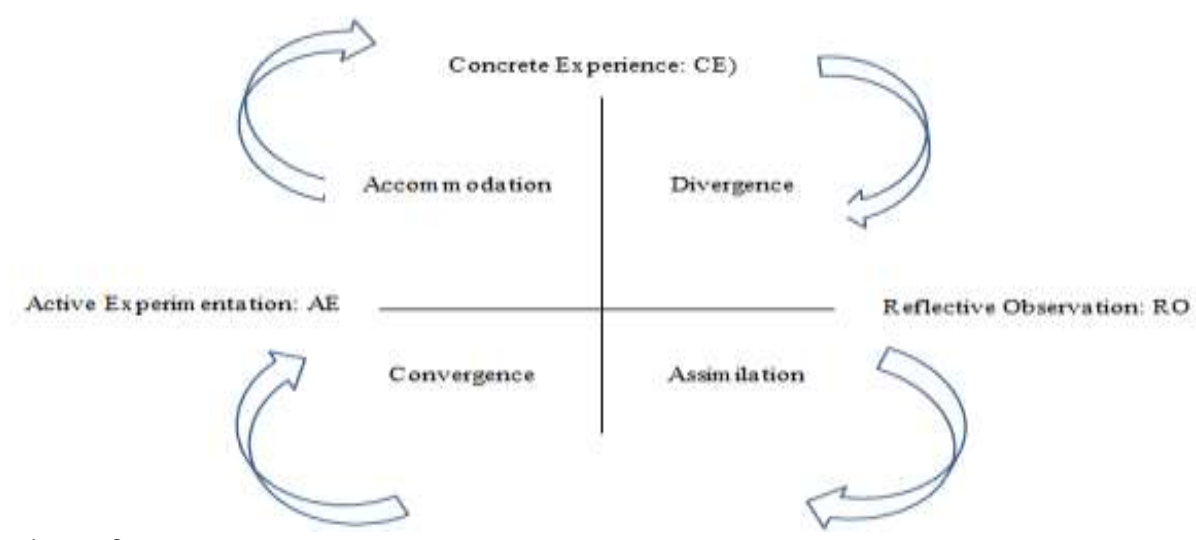

Figure 2

Learning Process ELT (Experiential Learning Theory) of People from the Concept of David A.Kolb and other(1984)

The concepts of learning above can be analysed as table 1 
Table 1

To Show an Analysis of the Conceptual Framework of the Research

\begin{tabular}{lccc}
\hline Learning Process & Bandura & Robert M. Gagné & David A.Kolb and other \\
\hline - Attention & $\bullet$ & $\bullet$ & $\bullet$ \\
-Attention; selective perception & & & \\
- Concrete experience & & & \\
-Reflective observation & & \\
\hline - Retention & $\bullet$ & \\
- Coding & & \\
-Memory storage & & $\bullet$ \\
\hline - Reprodution & $\bullet$ & & $\bullet$ \\
- Responding & & \\
- Retrieval & & \\
-Abstract Conceptualization & & $\bullet$ \\
andconclusion principle & & \\
\hline - Motivation & $\bullet$ & $\bullet$ \\
- Reinforcement & \\
\hline - Expectation & \\
\hline - Transfer & \\
-Active experimentation &
\end{tabular}

The researcher analysis table according to the frequency of variable and then can be synthesized to be concept framework of the research that the learning process of the undergraduate students consisted of six factors and each factor has meaning as follows

1. The expectation is desire, goal, and to specify the time, planning of learning, and to understand the goals of the undergraduate students

2. Attention, choosing to know by using experience, and reflective observation is that the undergraduate students communicate with their parents and teachers about guideline to improve learning grade, to study the stories of those who succeeded, to participate learning activities, to practice many skills to prepare themselves to work, to review and considerate their action each day, and to study and prepare learning equipment before learning.

3. Data recognition and storage is behavior of the students in following the content and lesson in the class and always concentrate to learning, note the content and information that the teachers lectured in many forms, having notebooks for each subject and review the lesson from the notebooks, to record lecturing of the teachers and review the recorded lecture.

4. Retrieval by reproduction or making concept by conclusion principles is behavior of the students in using the knowledge from the lesson to do homework or report, to understand the principles of each subject, can conclude the content of each subject by their own language, can transfer their knowledge to friends, and can make question then find the answer by themselves.

5. Transfering by experiment or application is the behavior of the students in using the knowledge to decide and solve the problem involved with learning in other subject and 
problem in daily life, to exchange opinion and answer the question of classmates, and to find advantages and way to use knowledge in the class in their daily life.

6. Motivation or reinforcement is expectation of the students to their parents and teachers in feedback, that the teachers tell them the score after testing, to make compliment about their homework, learning grade and right action, giving them prize when they have good learning grade, and the students like to join the competition activities to get the prize).

\section{METHOD}

Study process to find the learning model of the undergraduate students is divided into two phrases.

\section{The $1^{\text {st }}$ phrase :the preliminary study}

The first step was the basic study to find the exploratory factor of the learning process of the undergraduate students. The research used the concept of Hair to specify the size of sample groups that if the variables have the value from 0.30 up, the number of sample amount should be from 350 up. The researcher used Stratified Random Sampling and the faculties and year to classify. The five items rating scale questionnaire was used to collect the data, which composed of six components and 54 items, as follow;

The $1^{\text {th }}$ component: Expectation ( 9 items)

The $2^{\text {nd }}$ component: Attention, choosing to know by using experience, and reflective observation (12 items)

The $3^{\text {rd }}$ component: Data recognition and storage (14 items)

The $4^{\text {th }}$ component: Retrieval by reproduction or making concept by conclusion principles (6 items)

The $5^{\text {th }}$ component: Transfering by experiment or application ( 5 items)

The $6^{\text {th }}$ component: Motivation or reinforcement ( 8 items)

The content validity was at $0.67-1.00$, and the reliability was the way of Cronbach's Alpha Coefficient ]14[. The coefficient Alpha was 0.952, and the researchers analysed the data with Exploratory Factor Analysis :EFA by way of Varimax. The criteria to consider the factors was Eigen Value $\leq 1.00$ and considered that the factor loading has to be from 0.30 up. The primary study result to find the exploratory factors of the learning process of the undergraduate students shown in Table 2. 
Table 2

To Show the Exploratory Factor of the Learning Process of the Undergraduate Students

\begin{tabular}{|c|c|c|}
\hline Factors & Eigenvalues & Variables \\
\hline $\begin{array}{l}\text { 1. Retrieval by reproduction or making concept by } \\
\text { conclusion principles (Before analysis by EFA } \\
\text { composed of } 6 \text { items) }\end{array}$ & 16.601 & 4 \\
\hline $\begin{array}{l}\text { 2. Planning by experience and reflective observation } \\
\text { (Before data analysis: } 3 \text { variables of Expectation, and } \\
11 \text { items of Attention, choosing to know by using } \\
\text { experience, and reflective observation) }\end{array}$ & 3.417 & 14 \\
\hline $\begin{array}{l}\text { 3. Attention, retention, and memory storage } \\
\text { (Before data analysis: } 1 \text { variables of Attention, } \\
\text { choosing to know by using experience, and reflective } \\
\text { observation, and } 10 \text { variables of data recognition and } \\
\text { storage) }\end{array}$ & 2.526 & 11 \\
\hline $\begin{array}{l}\text { 4. Motivation or reinforcement } \\
\text { (Before analysis by EFA composed of } 8 \text { items) }\end{array}$ & 2.262 & 8 \\
\hline $\begin{array}{l}\text { 5. Expectation } \\
\text { (Before analysis by EFA composed of } 9 \text { items) }\end{array}$ & 1.851 & 6 \\
\hline $\begin{array}{l}\text { 6. Learning method } \\
\text { (Before data analysis: } 3 \text { variables of data recognition } \\
\text { and storage, when considering all } 3 \text { variables are } \\
\text { related to learning methods) }\end{array}$ & 1.527 & 3 \\
\hline
\end{tabular}

Note: Kaiser-Meyer-Olkin Measure of Sampling Adequacy $=.921$ and Bartlett's Test of Sphericity was at the 0.05 level of significance.

\section{The $2^{\text {nd }}$ phrase :Confirmatory Factor Analysis (CFA)}

The second phase aimed to find a learning model for undergraduate students. The sample groups were 377 undergraduate students of KMITL in the academic year 2557. The research used the concept of Hair to specify the size of sample groups that if the variables have the value from 0.30 up, the number of sample amount should be from 350 up. The researcher used Stratified Random Sampling and the faculties and year to classify. The five items rating scale questionnaire was used to collect the data, which composed of six components and 47 items and to examine concordance of the structural model by Confirmatory Factor Analysis (CFA) (Jöreskog, K. G., \& Moustaki, I., 2001).

\section{FINDINGS}

The secondary Confirmatory Factors of the Learning Model of Undergraduate Students are described in this section .The symbols used are as follows:
$\mathrm{LM}=$ Learning Model
$\mathrm{H}=$ Expectation (Variables $\mathrm{H} 1$ to H6)
$\mathrm{P}=$ Planning by experience and reflective observation )Variables P7 to P20(
$\mathrm{D}=$ Attention, retention and memory storage) Variables D21 to D31(
$\mathrm{L}=$ Learning method) Variables L32 to L34( 
$\mathrm{B}=$ Retrieval by reproduction or making concept by conclusion principles )Variables B35 to B38(

$\mathrm{M}=$ Motivation or reinforcement (Variables M39 to M46)

Investigation of the goodness-of-fit of the causal model of the variables affecting of the Learning Model of Undergraduate Students corroborates with the empirical data. This is confirmed by; $x^{2}=674.50, x^{2} / \mathrm{df}=0.95, \mathrm{df}=712, \mathrm{p}$ value $=0.84, \mathrm{GFI}=0.93, \mathrm{AGFI}=$ .89 and RMSEA $=0.000$, which are based on the specified criteria (see Table 2).

Table 2

The Goodness-of-fit of the Causal Model of the Variables Affecting of the Learning Model of Undergraduate Students Corroborates with the Empirical Data

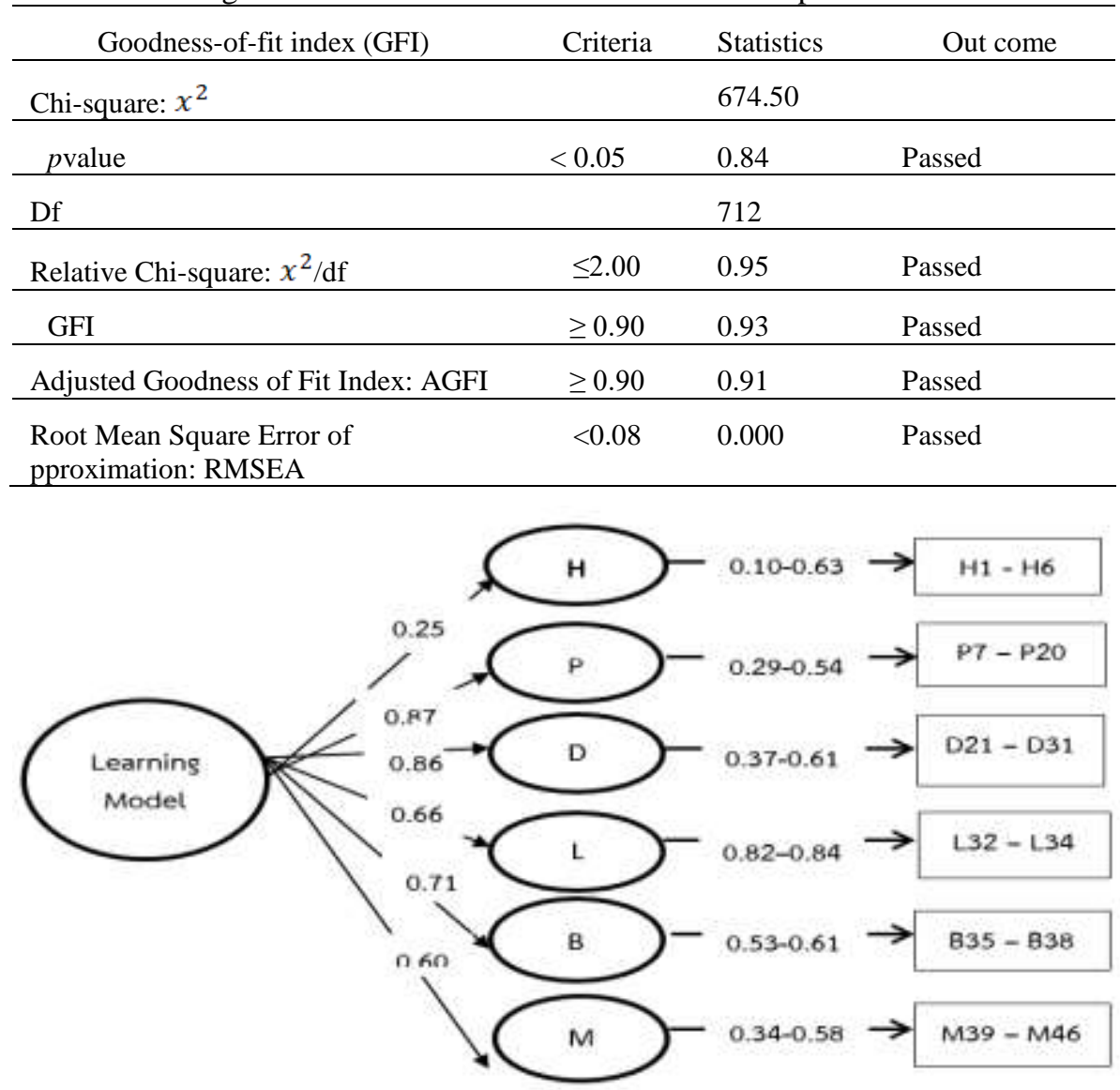

Figure 2

CFA of the Causal Relationships of the Learning Model of Undergraduate Students 
Figure 2 shows the CFA of the six observed variables for the Learning Model of Undergraduate Students are (1) expectation $=0.25$ (2) planning by experience and reflective observation $=0.87$ (3) attention, retention and memory storage $=0.86$ (4) learning method $=0.66(5)$ retrieval by reproduction or making concept by conclusion principles $=0.71$ and $(6)$ motivation or reinforcement $=0.60$ The composition by weight of each variable had a statistical significance level at 0.05 as shown in Figure 2.

Result of Confirmatory Factors Analysis of the factor expectation which consisted of six visible variables; 1) the learners studies at the institution because they would like to have good occupation in the future, 2) the learners studies at the institution because they realize that the knowledge from the institution was meaningful and useful for their social status in the future, 3) the learners studies at the institution because they need knowledge, 4) the learners studies at the institution by their own decision, 5) the learners clearly specified the period of learning in the Bachelor degree, and 6) the leaners like that the teachers clearly informed learning detail in each subject before starting learning. All variables had standard factors value at $0.29,0.63,0.43,0.47,0.24$ and 0.10 , and the values of the standard factor of all variables were at the 0.05 level of significance.

Result of Confirmatory Factors Analysis of the factor expectation which consisted of 14 visible variables; 1) the learners imitated lifestyle of the successful people, 2) the learners communicated with the teachers about guideline to improve their learning grade, 3) the learner studied the stories of the people who succeeded in learning, 4) the learners studied the stories of the people who succeeded in occupation, 5) the learners planned their steps of learning in each semester clearly, 6) the learners like to observe learning steps of the successful classmates, 7) the learners communicate with the parents about the guideline to improve their learning grade, 8) the learners talk with classmates about the guideline to improve their learning grade, 9) the learners considered their behaviour or action each day, which one was good and bad, 10) the learners joined the activities that support learning such as reading, searching information in internet and many more, 11) the learners specified their average grade of learning in every semester as the goal that they must achieve, 12) the learners ask questions about the assigning job to ensure that they understand the job well and clearly, 13) the learners studied the lesson before learning in the class, and 14) the learners practice many professional skills to prepare themselves for the occupation in the future. All variables had standard factors value at $0.29,0.38,0.37,0.32,0.30,0.41,0.45,0.50,0.47,0.48,0.34,0.46,0.54$ and 0.49 , and the values of standard factor of all variables were at the 0.05 level of significance.

Result of Confirmatory Factors Analysis of the factor attention, retention and memory storage which consisted of eleven visible variables; 1) the learners noted the content in the lesson that the teachers lectured in the form of letters, 2) the learners noted the content in the lesson that the teachers lectured in the form of abbreviation or symbols, 3) the learners had notebooks for each subject, 4) the learners sat at the position that can see the lecturing content clearly, 5) the learners prepared all equipment before learning, $6)$ the learners concentrated on learning, 7) the learners reviewed the lesson from the lecture notebook, 8) the learners noted the content in the lesson that the teachers 
lectured in the form of letters and pictures, 9) the learners did not do any other activities except learning during in the class, 10) effective media with picture helped the learners to remember better, and 11) the learners noted the content in the lesson that the teachers lectured in the form of mind mapping. All variables had standard factors value at 0.46 , $0.50,0.47,0.47,0.37,0.53,0.54,0.58,0.61,0.53$ and 0.52 , and the values of standard factor of all variables were at the 0.05 level of significance.

Result of Confirmatory Factors Analysis of the factor expectation which consisted of three visible variables; 1) the learners listened to the lecture sound of the teachers to review the lesson, 2) the learners recorded the lecture of the teachers, and 3) videos helped the learners to memorize the content in the lesson better. All variables had standard factors value at $0.82,0.84$ and 0.83 , and the values of standard factor of all variables were at the 0.05 level of significance.

Result of Confirmatory Factors Analysis of the factor expectation which consisted of four visible variables; 1) the learners can concluded the content of each subject with their own language, 2) the learners can transfer the knowledge to the classmates, 3) the learners used the knowledge from the lesson to do reports and assignments, and 4) the learners used the knowledge from the lesson to do homework. All variables had standard factors value at $0.53,0.55,0.53$ and 0.61 , and the values of the standard factor of all variables were at the 0.05 level of significance.

Result of Confirmatory Factors Analysis of the factor expectation which consisted of eight visible variables; 1) the learners were glad when the parents complimented them about their learning grade, 2) the learners were glad when the teachers complimented about their good manner and behaviour, 3) the learners were glad when the teachers complimented them about their learning grade, 4) the learners were glad when their test result met their goal, 5) the learners liked that the teachers told the score to them after testing, 6) the learners liked when the parent gave them a prize because of their good learning grade, 7) the learners liked that the teachers gave them feedback or suggestion about their homework or assignments, and 8) the learners liked the competition activities because they got the prize. All variables had standard factors value at $0.46,0.50,0.46$, $0.34,0.45,0.52,0.58$ and 0.58 , and the values of standard factor of all variables were at the 0.05 level of significance.

\section{CONCLUSION AND DISCUSSION}

The overall research result found that the learning model of undergraduate students consisted of six factors; 1) expectation, 2) planning by experience and reflective observation, 3) attention, retention and memory storage, 4) learning method, 5) retrieval by reproduction or making concept by conclusion principles, and 6) motivation or reinforcement. The first learning step found from the research of learning model is "expectation" that is consistent with the concept of Gagné (1974), who stated that the first step of learning is that the teachers have to motivate the learners to expect and define learning goals. The second learning step found from the research is "planning by experience and observation", which is consistent with the concept of David A.Kolb and other, (1984) who stated that the first learning step is learning from concrete experience 
and material objects, and the second step is learning from reflective observation. The third learning step found from the research is "attention, retention and memory storage", which is consistent with the concept of Bandura (1971), who presented that the first learning step is attention to choose motivation and the second step is retention. Also, it is consistent with the concept of Gagné (1974), who stated that the second step of learning is attention and selective perception and the fourth step is memory storage. The fourth learning step found from the research is "learning method", which is not consistent with any academician, whose concept used in the research. However, the learning method is a tool or guideline that the learners use to support good memorising and data collection. The fifth learning step found from the research is "retrieval by reproduction or making concept by conclusion principles" that is consistent with the concept of Gagné (1974), who stated that the fifth step is retrieval, the sixth step is to transfer, and the seventh step is responding. Also, it is consistent with the concept of Bandura (1971), who stated that the third step is a reproduction. Besides, it is consistent with the concept David A.Kolb and other (1984), in the third step; abstract conceptualisation and conclusion in principles as well as the learning process. Finally, the sixth learning step found from the research is "motivation and reinforcement" that is consistent with the concept of Bandura (1971). in the fourth step; motivation. Also, it is consistent with the concept of Gagné (1974) in the eighth step stated reinforcement.

The first-factor "expectation" consisted of six visible variables. It was stated that the learners could learn well when they have the expectation. The expectation can be material or any payment, in order to motivate the learners to try their best to meet the settled goals and gain the prize. Therefore, the teachers should specify learning outcomes because learning outcomes as useful learning aids and that student use them in various ways to support their studies. (Sara Brooks and others , 2014) Three strategies are synthesized as the ISEE framework: (1) employing Inquiry-based Scaffolding Tasks to motivate students' learning interests and scaffold their progress; (2) encouraging Engaging Classroom Dialogs to help students' development of subject expertise and an active learner identity; and (3) using Engaged Critical Reflections to build close and trusting teacher-student relationships.(Min Yang, 2015).

The second-factor "planning by experience and reflective observation" consisted of 14 variables. It was stated that to meet the settled goal, and there must be planning. Good planning is to study all data both direct and indirect and then considerate the data carefully. Therefore, if the teachers describe the learning outcome to the learners, then they will be able to plan alignment and pass at their targeted grade.[15]Moreover, The teachers must understand that students come to us with the explicit hope that what we offer will lead to a better and more prosperous life. Moreover, in order to improve learning quality, the teachers should move from the concept of "making a living"finding, knowing, memorising, testing, amassing, to "making a life"-applying, practising, producing, engaging, contributing, and creating. (Margit Misangyi Watts, 2016).

The third-factor "attention, retention and memory storage" consisted of eleven variables. It was stated that good learning is to pay attention by observation, retention and memory 
storage in the form of symbols or letters because retention is knowledge storage. When it is time to do homework, project or training, the undergraduate students will be able to use and adapt the collected and memorised knowledge. Therefore, teaching media with picture will help the learners to memorise the content better. On the other hand, teachers who possess knowledge about their students' learning styles help them to give supporting ideas in explaining the learning materials, and how to use multiple learning strategies. (Ghusoon Salim Basheer and others, 2016).

The fourth-factor "learning method" consisted of three variables. A learning method is a tool or guideline for learners to memories and collect data better and longer. Therefore, learning Media, learning resources or books, and learning materials are tools used by teachers in the learning process to help convey the message of learning and to facilitate students in interacting meaningfully and effectively within their sociocultural and physical environments. (Erni Ratna Dewi., 2018) and (Peter E. Doolittle, 2014).

The fifth-factor "retrieval by reproduction or making concept by conclusion principles" consisted of four variables. It was stated that retention is a process that the learners change the symbol of attention, memorise from the model and then imitate to link the learning in the form of concept or principles. Therefore, if the students can see, taste, feel, hear, and touch the objects or items, then learning will have a greater and deeper meaning for students. (Lilia Gomez-Lanier, 2017).

The sixth-factor "motivation and reinforcement" consisted of eight variables. It was stated that feedback would show the students how good or bad is their action. If the action is good, it can be a motivation encouraging the students to keep learning. If the action is bad, it can be found the guideline to solve the problem onwards. The factor is consistent with the concept of Erni Ratna Dewi, stated that "it can be concluded that learning is a process of activities in which there is the interaction between teachers and students and students and students so that the students' behaviour changes to be proper behaviour." (Ghusoon Salim Basheer and others, 2016). Also İshak Kozikoğlu (2019) found that the interview form and survey were mostly used in the studies, the videos, presentations and written documents were used in out-of-class activities and practical activities were conducted in class. According to the study results, it is seen that flipped learning model has a positive effect on the students' academic achievement, motivation, metacognitive awareness, etc. Moreover, it was determined that students and teachers have positive views on flipped learning model.

\section{ACKNOWLEDGEMENTS}

This work is supported by the Annual income budget on 2014 by the Industrial Education and Technology Faculty, King Mongkut's Institute of Technology Ladkrabang (KMITL), Bangkok, Thailand.

\section{REFERENCES}

Bandura, A. (1971). Social learning theory. New York: General Learning Press. 
Basheer, G. S., Tang, A. Y. C., \& Ahmad, M. S. (2016). Designing teachers' observation questionnaire based on curry's onion model for students' learning styles detection. TEM Journal, 5(4), 515-521. DOI: 10.18421/TEM54-16.

Bolhuis, S. (2013). Towards process-oriented teaching for self-directed lifelong learning: A multidimensional perspective. Learning and Instruction, 13(3), 327-347.

Brooks, S., Dobbins, K., Scott, J. J. A., Rawlinson, M., \& Norman, R. I. (2014). Learning about learning outcomes: The student perspective. Teaching in Higher Education, 19(6), 721-733. http://dx.doi.org/10.1080/13562517.2014.901964.

Dewi, E. R. (2018). The effect of learning strategies, learning models, and learning innovation on educators' performance and education quality in senior high schools in Makassar. TEM Journal, 7(3), 548-555. DOI: 10.18421 /TEM73-10.

Doolittle, P. E. (2014). Complex constructivism: A theoretical model of complexity and cognition. International Journal of Teaching and Learning in Higher Education, 26(3), 485-498.

Gagné, R. M. (1974). Essentials of learning for instruction. Illinois: Prentice Hall.

Gagné, R. M., Briggs, L. J., \& Wagner, W. (1992). Principles of instructional design. New York: Harcourt Brace College Publishers.

Gomez-Lanier, L. (2017). The experiential learning impact of international and domestic study tours: Class excursions that are more than field trips. International Journal of Teaching and Learning in Higher Education, 29(1), 129-144.

Hair Jr, J. F., Blak, W. C., Barbin, B. J., \& Anderson, R. E. (2010). Multivariate data analysis. New Jersey: Pearson.

Jöreskog, K. G., \& Moustaki, I. (2001). Factor analysis of ordinal variables: A comparison of three approaches. Multivariate Behavioral Research, 36(3), 347-387. Higher Education, 22. https://doi.org/10.6017/ihe.2001.22.6906.

King Mongkut's Institute of Technology Ladkrabang (KMITL). (2019). History of institute. Retrieved from http://www.kmitl.ac.th. /about.main.php.

Kolb, D. A., Rubin. I. M., \& McIntyre, J. M. (1984). Organizational psychology: Readings on human behavior in organizations. New Jersey: Prentice-Hall.

Kozikoğlu, İ. (2019). Analysis of the studies concerning flipped learning model: A comparative meta-synthesis study. International Journal of Instruction, 12(1), 851-868.

Kehm, B. (2001). The challenge of lifelong learning for higher education. International

Knapper, C. K., \& Cropley, A. J. (2000). Lifelong learning in higher education. London: Kogan Page.

Office of The Education Council. (2017). Ranking and value of IMD by education indicators 18 Indicators in 2013 - 2017. Retrieved from 
http://backoffice.onec.go.th/uploaded/Category/Evaluation/Evaluation2017-07-05-IMD56-60.pdf.

Office of The Higher Education Commission. (2556). Higher education development plan no. 11 (2012-2016). Bangkok, Thailand.

The United Nation. (2015). The sustainable development agenda. Retrieved from https://www.un.org/sustainabledevelopment/education/.

UNESCO. (2016). Strategy for technical and vocational education and training (TVET) 2016-2021. Paris: UNESCO.

Watts, M. M. (2016). Personalizing Learning. New Directions for Teaching and Learning, 145, 17-24. DOI: 10.1002/t1.20170.

Yang, M. (2015). Promoting self-sustained learning in higher education: The ISEE framework. Teaching in Higher Education, 20(6), 601-613, http://dx.doi.org/10.1080/13562517.2015.1052785. 